Bond University

Research Repository

\title{
Supraclavicularis proprius muscle associated with supraclavicular nerve entrapment
}

Raikos, A.; English, Thomas; Agnihotri, A.; Yousif, Omar Khalid; Sandhu, M.; Bennetto, J.; Stirling, A.

Published in:

Folia Morphologica

DOI:

10.5603/FM.2014.0081

Licence:

CC BY-NC-ND

Link to output in Bond University research repository.

Recommended citation(APA):

Raikos, A., English, T., Agnihotri, A., Yousif, O. K., Sandhu, M., Bennetto, J., \& Stirling, A. (2014).

Supraclavicularis proprius muscle associated with supraclavicular nerve entrapment. Folia Morphologica, 73(4), 527-530. https://doi.org/10.5603/FM.2014.0081

\section{General rights}

Copyright and moral rights for the publications made accessible in the public portal are retained by the authors and/or other copyright owners and it is a condition of accessing publications that users recognise and abide by the legal requirements associated with these rights.

For more information, or if you believe that this document breaches copyright, please contact the Bond University research repository coordinator. 


\title{
Supraclavicularis proprius muscle associated with supraclavicular nerve entrapment
}

\author{
A. Raikos, T. English, A. Agnihotri, O.K. Yousif, M. Sandhu, J. Bennetto, A. Stirling \\ Faculty of Health Sciences and Medicine, Bond University, Gold Coast, QLD, Australia
}

[Received 13 February 2014; Accepted 28 March 2014]

\begin{abstract}
Entrapment neuropathy of the supraclavicular nerve is rare and, when it occurs, is usually attributable to branching of the nerve into narrow bony clavicular canals. We describe another mechanism for entrapment of this nerve with the aberrant muscle; supraclavicularis being found during the routine dissection of an embalmed 82-year-old cadaver. Our report details a unique location for this rare muscular variation whereby the muscle fibres originated posteriorly on the medial aspect of the clavicle before forming a muscular arch over the supraclavicular nerve and passing laterally towards the trapezius and acromion. We recommend that in clinical instances of otherwise unexplained unilateral clavicular pain or tenderness, nerve compression from the supraclavicularis muscle must be borne in mind. (Folia Morphol 2014; 73, 4: 527-530).
\end{abstract}

Key words: entrapment, impingement, supraclavicular fossa, supraclavicular neuropathy, supraclavicularis proprius, supraclavicular triangle, lateral neck

\section{INTRODUCTION}

The region around the clavicle in the lateral neck is an area where muscular anatomical variations of many diverse origins and forms have been noticed. The supraclavicularis proprius (SP) is one such variation however it has only been reported in a few instances $[1,14]$ with its pictorial documentation being very limited. The muscle usually originates from the clavicle near the sternoclavicular joint (SJ) and crosses lateral to the sternocleidomastoid muscle (SM) [6, 14]. It courses posteriorly to insert onto the lateral third of the clavicle and onto trapezius muscle. The origin of the muscle can be from variable positions such as the superior border of the clavicle, close to the SJ [11], or from the posterior border of the clavicle, close to the SJ as described in our report.

Gruber was the first to describe a muscle of this variation, originally calling it the tensor fascia colli [11]. Since its initial description, the literature has yielded little information on SP incidence and clinical significance. A relevant study gives an incidence of only $0.64 \%$ as it was found in one out of 156 supraclavicular fossae examined [14]. The innervation of the aberrant muscle is usually from small neuronal twigs arising from the supraclavicular nerve (SN) [11, 14]. Ottone et al. [14] suggest that the SP muscle develops from the embryological predecessor of the trapezius and SM. The existing literature has not yet reported on the vascular supply to the muscle.

Due to its anatomical course, the contraction of the SP muscle could result in significant clinical consequences. The SN may pass immediately under the muscle, through a tight space created between the muscle fibres and the superior border of the clavicle. Contraction of this aberrant muscle could result in compression of the $\mathrm{SN}$, referred in the literature as SN entrapment syndrome. The compression phenomena may evoke shoulder pain and anterior chest numbness $[2,7]$. 
This study aims to present a rare case of SP muscle which is co-related with SN entrapment in the supraclavicular fossa. We provide a detailed description on the topography and morphometry of the aberrant muscle, as well as on the branching pattern of the SN. We discuss the clinical correlations of such an aberrant musculature and review the current literature.

\section{CASE REPORT}

During the routine educational dissection of an 82-year-old male cadaver, a variation of the normal supraclavicular muscular anatomy was noticed in the lateral neck region adjacent to the clavicle. Further dissection was performed for the purpose of exposing the muscle and surrounding structures whilst preserving the nearby neurovascular structures.

The aberrant muscle was located in the right major and minor supraclavicular fossa and composed of two parts. The medial third was tendinous and the lateral two thirds were muscular. Anatomical measurements were performed using digital imaging processing software (ImageJ, ver 1.46r, NIH, Maryland, USA). The average width of the tendon was $1.8 \mathrm{~mm}$. The muscle had a total length of $120.7 \mathrm{~mm}$ and a width of $6.5 \mathrm{~mm}$ at it widest portion. The muscle originated from the posterior aspect of the clavicle, lateral to the SJ. It had an oblique course and ran parallel to the clavicle crossing the supraclavicular fossa from one end to the other. The length of the clavicle was $157.8 \mathrm{~mm}$. After its common tendon, the muscle split into 3 narrow slips, one inserting onto the anterior border of the trapezius, one onto the acromion and the last one onto the lateral aspect of the clavicle close to the acromion (Fig. 1).

The muscle courses along the top of the SNs, at the point where 4 secondary branches of the nerve become distinct (Fig. 2). The splitting of the SN was located $21.6 \mathrm{~mm}$ superior to the clavicle, and only a couple of millimetres away from the SP. The nerve lay superficial to the deep cervical fascia with a width of $9 \mathrm{~mm}$ before its division into 4 distinct branches. The branches provided sensory innervation to the skin in the superior pectoral, acromial, anterior deltoid, and infero-lateral neck region.

The orientation and position of the aberrant muscle formed a muscular arch for the passage of the SN and its branches. We noticed that the space under the arch was very limited and the nerve passing underneath could easily impinge evoking symptoms of nerve entrapment. That was confirmed after

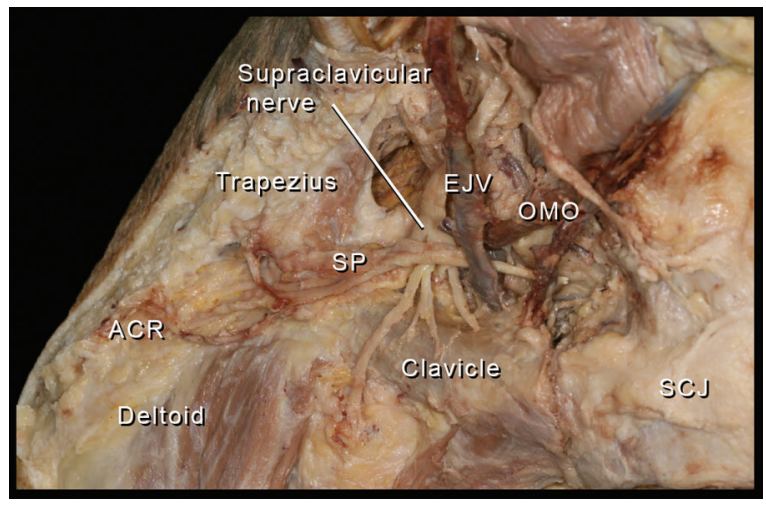

Figure 1. The supraclavicularis proprius (SP) courses in parallel with the clavicle, while the supraclavicular nerve passes under the arch formed by the aberrant muscle. The area under the muscular arch forms a narrow passage for the nerve and its secondary branches leaving them vulnerable to excessive traction or stretching. Note the proximity of the division of the supraclavicular nerve to the clavicle; EJV - external jugular vein; ACR — acromion; OMO — omohyoid; SCJ — sternoclavicular joint.

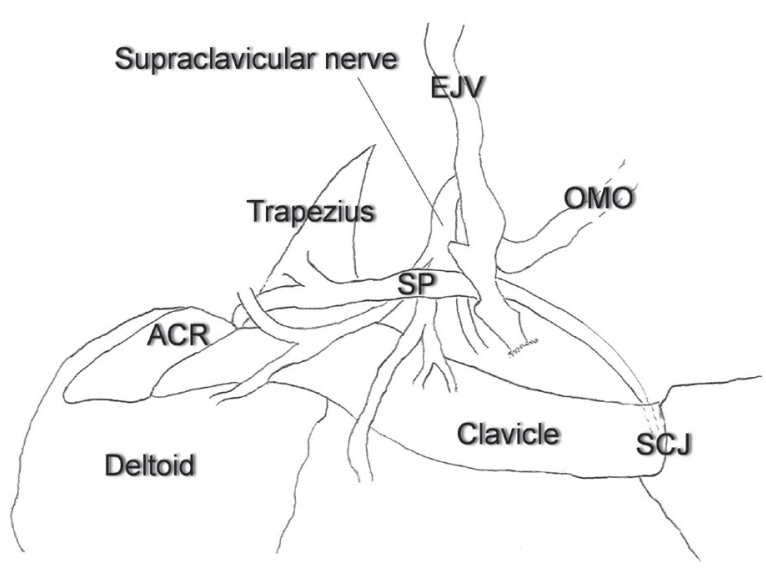

Figure 2. Schematic representation of Figure 1; abbreviations as in Figure 1.

moving the right upper limb into various positions. The remaining right cervical region had no further anomalies, while the left side of the neck was free from any variation.

\section{DISCUSSION}

The SP, although vary rare, has been described in the past with other names such as praeclavicularis subcutaneous and tensor fascia colli [11]. According to Testut, the muscle belongs to a group of superficial muscles called musculus cleido-aponevrotique ascendant [21]. The SP should be distinguished from other aberrant muscles of the lateral neck area. There are, for example, similarities in the muscle's orien- 
tation with the cleidotrachelian muscle. This muscle however is orientated postero-medially, and merges with longus colli muscle at C3-C4 level [13]. Differential diagnosis should be made from other aberrant muscles that might appear in the region such as the cleido-occipitalis [10], sternoclavicularis anticus [18], retroclavicularis proprius [1], sternoclavicularis superior [20], and supraclavicularis singularis [8]. The function of the muscle is unknown; however action on tensing the fascia of the neck has been suggested [11].

The origin and insertion of similar muscles in the clavicular region is variable. The origin of the SP is usually from the anterior portion of the clavicle, close to the origin of the SM [14]. In our case the origin was from the posterior aspect of the clavicle close to the $\mathrm{SJ}$ and passed deep to the anterior and external jugular vein. To the best of our knowledge the origin of the muscle in our case is unique and has not been reported in the literature before.

Impingement of the SN could be evoked from muscular and fibrous bands crossing the nerve, clavicular canals where the nerve passes through, clavicular fractures, and callus formation following clavicular fracture $[7,9]$.

The SN entrapment syndrome was been defined for the first time by Gelberman et al. [5] and described as mid-clavicular pain or tenderness following pressure on the middle third of the clavicle due to a compression of the nerve in its course. This is accompanied by numbness in the anterior part of the shoulder and in the area under the middle third of the clavicle. The triad of numbness, pain, and tenderness over the mid-clavicle, antero-medial shoulder and proximal chest are commonly experienced in this syndrome. The muscle can coexist with other aberrant anatomy in the neck region such as fibrous bands to adjacent muscles and thyroid gland anomalies [11].

Previous cadaveric and imaging studies have revealed the presence of canals in the clavicle through which the nerve traverses $[7,16,19]$. SN entrapment syndrome can also be caused by an aberrant fibrous band attaching the SN to the superior surface of the clavicle [16].

The paths of the medial and intermediate SN between the muscle and the superior surface of the clavicle have been observed in the description of the SP given by Eisler [3]. The variant anatomical structure described in our study forms a narrow passage through which the SN passes. Such openings are clinically re- levant as they may facilitate the development of an entrapment neuropathy $[4,15]$.

The SN in our case divided into secondary branches almost at the same level as the aberrant muscle instead of dividing and spreading in a distance from the clavicle as described before [12]. We believe that this might have a further effect on the production of compression phenomena.

Supernumerary muscles around the supraclavicular fossae possess surgical and radiological significance as well. The presence of aberrant muscles in the region may limit surgical access during dissection for removal of cervical lymph nodes in lymphadenectomy and accessing the neurovascular elements in the region. Furthermore, the standard topographical landmarks of the neck might be altered in ultrasonography of the region and mislead diagnosis [17]. Surgical decompression of the SN should be sought in cases with muscle wasting, persisting pain in the anterior shoulder region, and unsuccessful management with conservative means of therapy $[2,4]$.

\section{CONCLUSIONS}

Although rare, when present, the SP is significant in causing an entrapment neuropathy due to excessive traction or stretching of the SN. Thus, for patients presenting with otherwise unexplained unilateral pain, paraesthesia, or numbness in the anterior shoulder and clavicular region, the possibility of anatomical variations such as the aberrant muscle described in this report should be borne in mind.

\section{REFERENCES}

1. Bergman RA, Thompson SA, Afifi AK, Saadeh FA (1988) Compendium of human anatomic variation. Urban \& Schwarzenbeg, Rio de Janeiro, p. 607.

2. Douchamps F, Courtois AC, Bruyere PJ, Crielaard JM (2012) Supraclavicular nerve entrapment syndrome. Joint Bone Spine, 79: 88-89.

3. Eisler P (1912) Die Muskeln des Stammes. Gustav Fischer Verlag, Jena.

4. Fisher M, Gorelick P (1985) Entrapment neuropathies: Differential diagnosis and management. Postgrad Med, 77: 160-174.

5. Gelberman R, Verdeck W, Brodhead W (1975) Supraclavicular nerve-entrapment syndrome. J Bone Joint Surg Am, 57: 119.

6. Hyrtl J (1858) Zwei Varianten des Musculus sterno-clavicularis. Sitzungsberichte der K K Akademie in Wien, 29: 265-269.

7. Jelev L, Surchev L (2007) Study of variant anatomical structures (bony canals, fibrous bands, and muscles) in 
relation to potential supraclavicular nerve entrapment. Clin Anat, 20: 278-285.

8. Jinguji Y, Takisawa A (1983) Rare case of $m$. supraclavicularis singularis (Gruber). Kaibogaku Zasshi, 58: 630-633.

9. Jupiter JB, Leibman MI (2007) Supraclavicular nerve entrapment due to clavicular fracture callus. J Shoulder Elbow Surg, 16: e13-e14.

10. Kwak HH, Kim HJ, Youn KH, Park HD, Chung IH (2003) An anatomic variation of the trapezius muscle in a Korean: the cleido-occipitalis cervicalis. Yonsei Med J, 44: 1098-1100.

11. Laidlaw $P$ (1902) A Supraclavicularis Proprius (Gruber). J Anat Physiol, 36: 417-418.

12. Mehta A, Birch R (1997) Supraclavicular nerve injury: the neglected nerve? Injury, 28: 491-492.

13. Newell RL (1991) An anomalous muscle crossing the supraclavicular triangle: the cleidotrachelian muscle. Surg Radiol Anat, 13: 231-233.

14. Ottone N, Medan C (2009) A rare muscle anomaly: the supraclavicularis proprius muscle. Folia Morphol, 68: 55-57.
15. Pratt $N$ (1986) Neurovascular entrapment in the regions of the shoulder and posterior triangle of the neck. Phys Ther, 66:1894-1895-1900.

16. Pühringer K (1920) Über Nervenkanäle des Schlüsselbeins. Sitzungsberichte der Akademie der Wissenschaften Wien, 129: 83-92.

17. Raikos A, Paraskevas G, Triaridis S, Kordali P, Psillas G, Brand-Saberi B (2012) Bilateral supernumerary sternocleidomastoid heads with critical narrowing of the minor and major supraclavicular fossae: clinical and surgical implications. Int J Morphol, 30: 927-933.

18. Sakuma E, Omi K, Takeda N, Hasegawa H, Mori K, Mabuchi Y, Soji T (2007) Bilaterally existing sternoclavicularis anticus muscles. Anat Sci Int, 82: 237-241.

19. Skarby HG (1936) Das Foramen Nervi Clavicularis im Röntgenbild. Acta Radiol, 17: 397-402.

20. Suzuki R (2006) Morphogenesis of the superior sterno-clavicular muscle and other supernumerary uncommon muscles in the superficial neck region. Niigata Med J, 120: 668-683.

21. Testut $L$ (1884) Les anomalies musculaires chez l'homme. Masson, Paris. 